\title{
我 \\ Qualidade Da Água E Potencial De Assoreamento Em Represas Com Influência De Diferentes Usos Do Solo
}

\author{
Water Quality And Potential Of Damping In Dams With The Influence Of Different Soil Uses
}

Amanda Gimenes Guimarães ${ }^{1}$; Fernando Santiago do Prado ${ }^{2}$; Gilmar Oliveira Santos ${ }^{3}$; Raisa Gomes Diniz ${ }^{4}$, Indiamara Marasca ${ }^{5}$, Carlos Henrique Maia ${ }^{6}$.

\footnotetext{
${ }^{1}$ Engenheira Ambiental - Universidade de Rio Verde- UniRV, Rio Verde - Goiás. amandagimenesg@hotmail.com

${ }^{2}$ Mestrando em Geografia na Universidade Federal de Goiás - UFG, Jataí- Goiás. fernandonextel7@gmail.com

3 Prof. Adjunto na Universidade de Rio Verde- UniRV, Rio Verde- Goiás

${ }^{4}$ Mestranda em Produção Vegetal na Universidade de Rio Verde- UniRV, Rio Verde- Goiás. raisadiniz@hotmail.com / (64) 3611-2278*

5 Prof. - Dra. Faculdade de Agronomia, Universidade de Rio Verde - UniRV, Rio Verde - GO. marasca@unirv.edu.br

${ }^{6}$ Engenheiro Ambiental pela Universidade Católica de Goiás - PUC- Goiás.
}

\section{Info}

Recebido: 06/06/2018

Publicado: $14 / 11 / 2018$

DOI: 10.29247/2358-260X.2018v5i3.p125-139

ISSN: 2358-260X

\section{Palavras-Chave}

disponibilidade hídrica, curso d'água, carreamento.

Keywords:

water availability, water sources, haulage.

\section{Resumo}

O mau uso do solo, a ocupação inadequada próxima aos mananciais e a ausência de Área de Preservação Permanente (APP), influencia diretamente a qualidade e a quantidade de água em uma bacia hidrográfica. 0 presente trabalho teve como objetivo avaliar a qualidade físicoquímica da água e o potenci al de assoreamento, por diferentes influências de usos do solo no município de Rio Verde, Goiás. Foram realizadas seis coletas de água em cada represa, sendo três no período chuvoso e três no período de estiagem, as amostras foram coletadas a jusante e a montante das represas. Os parâmetros avaliados foram $\mathrm{pH}$, condutividade elétrica (Ce), dureza total (DT), alcalinidade

(A), turbidez (TB) e sólidos totais (ST). No período chuvoso, os parâmetros analisados obtiveram concentrações maiores que no período de estiagem devido ao carreamento de partículas sólidas para o curso d'água, que contribuiu para a diminuição da qualidade e da quantidade da água. Houve maior degradação da qualidade físico-química na bacia 4, com uso e ocupação de solo urbanização/solo exposto, devido ao lançamento clandestino de esgoto, além de ser a bacia que possui o maior potencial de assoreamento, aproximadamente em 22 anos esta represa estará totalmente assoreada.

\footnotetext{
Abstract

Poor land use and an inadequate occupation close to the sources and absence of the Permanent Preservation Area (PPA) directly influence the quality and quantity of water in a river basin. The present work had as objective an evaluation of the physical-chemical quality of the water and potential of assertion by different influences of land uses in the municipality of Rio Verde, Goiás. Six water samples were collected in each dam, three of them without rainy period and three without estimation period, as samples were collected upstream and upstream of the dams. The parameters of $\mathrm{pH}$, electrical conductivity (EC), total hardness (HT), alkalinity (A), tusrbidity (TB) and total solids (TS). In the rainy season the analyzed parameters obtained concentrations greater than the period of estimation of the product of solid particles for the source that contributes diminishing of the quality and quantity of the water. There was a greater degradation of the physical-chemical quality in basin 4 with use and occupation of exposed urbanization/soil, due to the clandestine launch of sewage, besides being a basin has greater potential of silting in approximately 22 years is represented by a total of silted.
} 


\section{INTRODUÇÃO}

Os impactos resultantes da ação antrópica causam uma série de alterações na quantidade e qualidade dos recursos hídricos, alterando o ciclo hidrológico, causando impactos ambientais, econômicos e sociais. Deste modo conhecer a relação entre uso e ocupação do solo e qualidade da água é fundamental para a gestão de recursos hídricos (Paula et al., 2016).

Os recursos hídricos são essenciais na agricultura e nos abastecimentos urbanos e industriais, sendo a qualidade da água um aspecto básico para a redução de doenças de veiculação hídrica e maior produtividade nos setores primário e secundário (Aparecido et al., 2016).

A má conservação do solo e a expansão das áreas urbanas, associadas ao uso em conflito com as Áreas de Preservação Permanente (APP), influenciam diretamente na qualidade física e biológica dos mananciais. Desta forma, o monitoramento das águas é de fundamental importância para fins de se constituir um banco de dados, e ao mesmo tempo, identificar os elementos passíveis de afetar a indisponibilidade hídrica que, sem dúvida, constitui fator limitante para o desenvolvimento econômico de uma região por meio da agricultura irrigada (Santos e Hernandez, 2013).

Segundo Bucci (2015), o mau uso do solo, a ocupação das terras, a falta de vegetação, a degradação das APP e a ocupação inapropriada, próxima aos mananciais, são os principais fatores para a degradação de um corpo hídrico, reduzindo a qualidade do mesmo em uma bacia hidrográfica.

O ciclo hidrossedimentológico é um processo que ocorre naturalmente ao longo do tempo, podendo, no entanto, ser acelerado em consequência da ação antrópica, aumentando a produção de sedimentos de uma bacia. Os principais fatores que influenciam a produção de sedimentos na área de drenagem de uma bacia hidrográfica são: a precipitação, tipo de solo e formação geológica, cobertura do solo, uso do solo, topografia, escoamento superficial (Vanzela et al., 2012).

$\mathrm{O}$ uso de indicadores físicos, químicos e biológicos, é uma medida ambiental importante para viabilizar o uso múltiplo dos recursos hídricos, esses indicadores são usados para apresentar e controlar as alterações ocorridas na bacia hidrográfica (Freire et al., 2013).

A identificação do uso do solo e a determinação geográfica dos possíveis riscos, associados com as atividades antrópicas, constituem-se num importante instrumento de análise ambiental, o que pode ser utilizado para orientar programas de monitoramento ambiental (Lima et al., 2004).

Neste contexto, o presente trabalho teve como objetivo avaliar a qualidade físico-química da água e o potencial de assoreamento, por diferentes influências de usos do solo no município de Rio Verde, Goiás.

\section{MATERIAL E MÉTODOS}

\section{Caracterização do município}

O estudo foi realizado no município de Rio Verde, região Sudoeste do Estado de Goiás, Brasil, entre as coordenadas $17^{\circ} 15^{\prime} 58,98^{\prime \prime} \mathrm{S}, 51^{\circ} 41^{\prime} 43,08^{\prime \prime O}$ e 1809'38,01"'S, 50²1'49,04”O. Sua topografia é plana, levemente ondulada, com 5\% de declividade, com altitude média de $748 \mathrm{~m}$, em que predominam os Latossolos Vermelhos e Latossolos Vermelho Amarelos (Acqua et al., 2013). O município possui duas estações climáticas bem definidas: uma seca (maio a outubro) e uma chuvosa (novembro a abril) (Inmet, 2017). A região apresenta fisionomias de cerrado sensu stricto (formações savânicas) e cerradão (Rocha et al., 2014). 
O município faz parte da Bacia Hidrográfica do Rio Paranaíba, que tem como rede de drenagem principal o Rio Turvo e dos Bois (Comitê de Bacias Hidrográficas do Rio Paranaíba, 2015).

\section{Localização da área de estudo}

A escolha da área foi realizada por meio do programa Google Earth, para verificar quais possuíam influência de uso e ocupação do solo e facilidade de acesso. Foram avaliadas 4 represas de diferentes influências de uso e ocupação do solo (Tabela 1 e Figura 1).

Tabela 1 - Caracterização dos pontos de análise das represas do município de Rio Verde, Goiás.

\begin{tabular}{cccc}
\hline Bacia & Latitude & Longitude & Altitude $(\mathrm{m})$ \\
\hline 1 & $17^{\circ} 44^{\prime} 47,25^{\prime \prime} \mathrm{S}$ & $51^{\circ} 00^{\prime} 00,36^{\prime \prime} \mathrm{O}$ & 802 \\
2 & $17^{\circ} 44^{\prime} 42,83^{\prime \prime} \mathrm{S}$ & $50^{\circ} 59^{\prime} 48,85^{\prime \prime} \mathrm{O}$ & 802 \\
3 & $17^{\circ} 43^{\prime} 37,09 " \mathrm{~S}$ & $50^{\circ} 50^{\prime} 15,26^{\prime \prime} \mathrm{O}$ & 679 \\
4 & $17^{\circ} 48^{\prime} 16,21^{\prime \prime} \mathrm{S}$ & $50^{\circ} 56^{\prime} 21,36^{\prime \prime O}$ & 692 \\
\hline
\end{tabular}

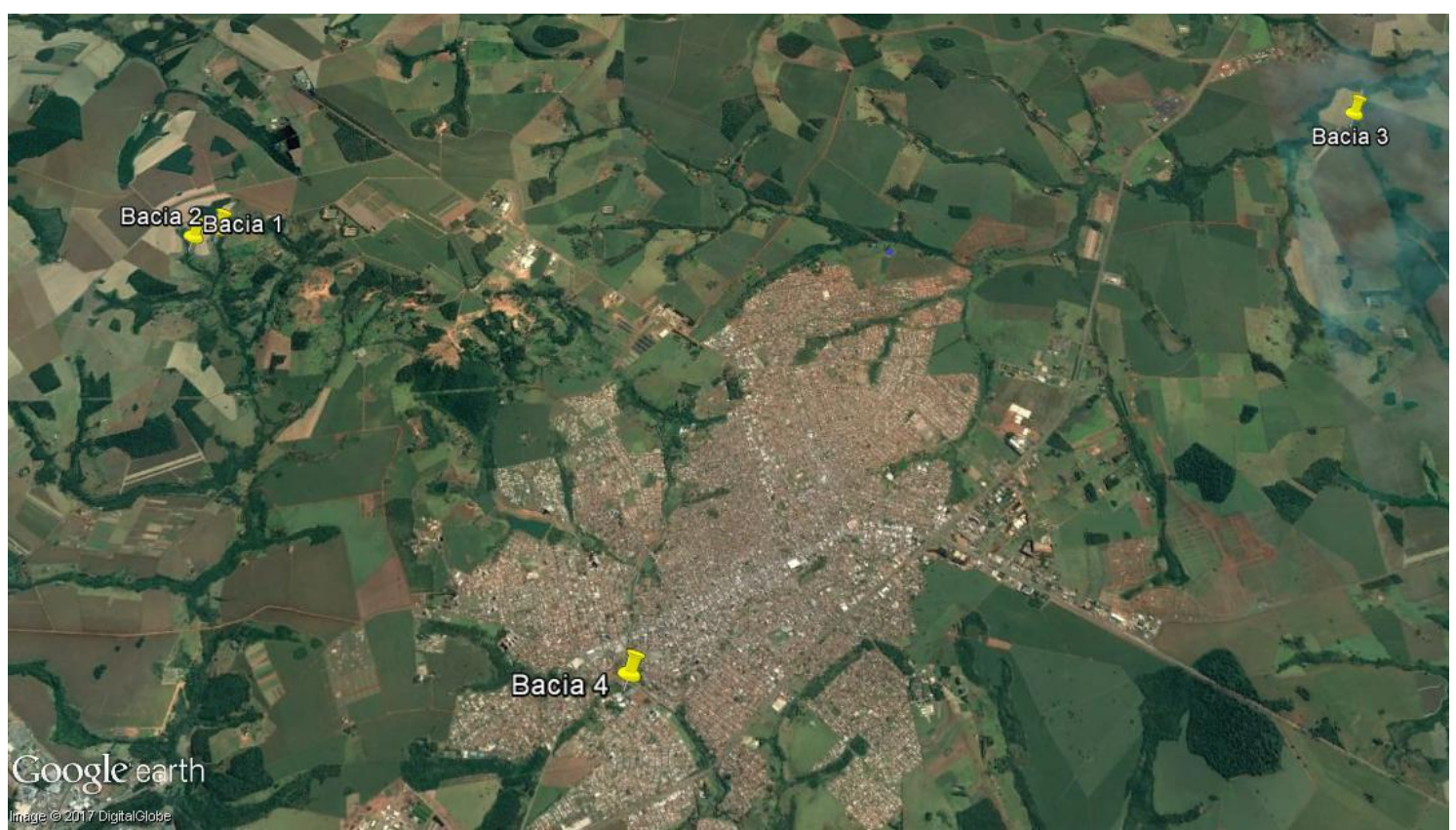

Figura 1 - Caracterização dos pontos de análise das represas do município de Rio Verde, Goiás.

Fonte: Google Earth e adaptados pelos autores, 2017.

$\mathrm{Na}$ criação dos mapas de uso e ocupação do solo, foi feito o download do shapefile da linha altimétrica, fornecida pelo site do IBGE, e as imagens de satélite da Digital Globe Empresa, adquiridas por meio do programa Google Earth PRO. Logo, em ambiente SIG, no software ARCMap 10.1, foi criado um novo shapefile para a delimitação das bacias hidrográficas, recorte das áreas de interesse (rasters) e classificação supervisionada para a classificação das feições contidas na imagem.

\section{Coleta e análise de águas}

Foram realizadas seis coletas de água em cada represa, sendo três no período chuvoso e três no período de estiagem. As amostras foram coletadas a jusante e a montante das represas (Figura 2), no período de janeiro a março (chuvoso) e julho a setembro 
(estiagem) de 2017, conforme estabelecido por Castro e

Santos (2018).

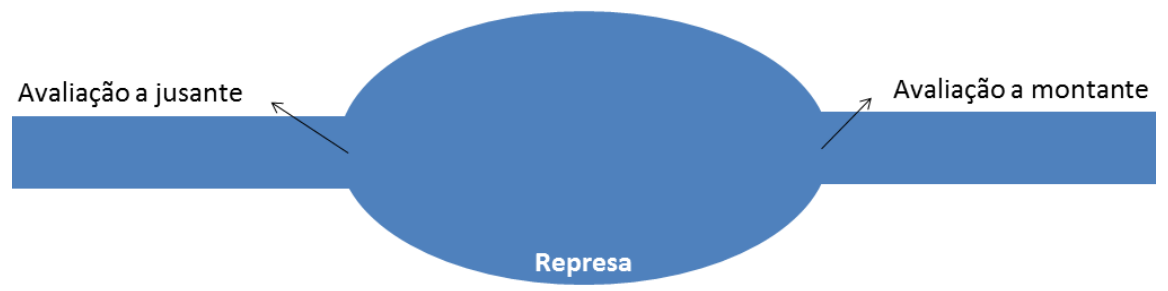

Figura 2 - Fluxograma da avaliação a jusante e a montante da represa.

As coletas foram realizadas de acordo com a NBR 9.898/1987, e foram acondicionadas em garrafas PET de dois litros, sendo que as mesmas foram higienizadas antes do procedimento. Após a coleta foram acomodadas em caixa de isopor com gelo e assim, encaminhadas para o laboratório da Universidade de Rio Verde, para a realização das análises de $\mathrm{pH}$, condutividade elétrica (Ce), dureza total (DT), alcalinidade (A), turbidez (TB) e sólidos totais (ST). Os ensaios foram realizados de acordo com as técnicas recomendadas pelo Standard Methods for the Examination of the Water and Wastewater (Apha, 2005; Tabela 2).

Tabela 2 - Síntese das metodologias, unidade de medida e limite de quantificação das análises da água para fins de irrigação.

\begin{tabular}{cccc}
\hline Parâmetros & Unidade de medida & Metodologia & Limite de quantificação \\
\hline Turbidez & $\mathrm{UNT}$ & Nefelometria & 0,1 \\
Alcalinidade & $\mathrm{mg} \mathrm{L}^{-1}$ & Titulometria & 0,01 \\
Dureza & $\mathrm{mg} \mathrm{L}^{-1}$ & Titulometria & 1 \\
Condutividade elétrica & $\mu \mathrm{S} \mathrm{cm}^{-1}$ & Eletrodo de platina & $0,1 \mu \mathrm{cm}^{-1} \mathrm{a} 25^{\circ} \mathrm{C}$ \\
$\mathrm{pH}$ & admensional & Eletrométrico & 0,01 \\
Sólidos totais & $\mathrm{mg} \mathrm{L}^{-1}$ & Gravimétrico & \\
\hline
\end{tabular}

\section{Potencial de assoreamento}

O potencial de assoreamento foi determinado por meio da quantidade de sedimentos que decantados na represa, com a relação da quantidade de sedimentos que estaria entrando e saindo da represa. Após conhecimento da quantidade decantada e vazão daquele curso d'água obteve-se assim o volume de sedimentos decantados (Equação 1).

$$
\mathrm{C}=\mathrm{Q} \cdot \mathrm{Cd} \quad \mathrm{Eq} \cdot: 1
$$

em que,

$\mathrm{C}=$ Carga de sedimentos decantados $\left(\mathrm{kg} \mathrm{d}^{-1}\right)$

$\mathrm{Q}=$ Vazão do curso d'água $\left(\mathrm{L} \mathrm{s}^{-1}\right)$

$\mathrm{Cd}=$ Concentração de decantação $\left(\mathrm{kg} \mathrm{L}^{-1}\right)$

\section{Medição de vazão}

A medição foi realizada pelo método flutuador. Por meio da divisão da variação de espaço $(\Delta \mathrm{S})$ pela variação de tempo $(\Delta \mathrm{T})$ obteve-se a velocidade média das represas de estudo. A medição da área de seção molhada foi obtida por meio do software AutoCAD. A vazão de escoamento foi obtida por meio da Equação 2.

No ponto 1, a represa possui um vertedouro que é canalizado, local onde foi avaliado a vazão de escoamento $\left(\mathrm{m}^{3} \mathrm{~s}^{-1}\right)$, que foi determinada por meio de um recipiente de volume conhecido pelo tempo gasto.

$$
\mathrm{Q}=\mathrm{V} \cdot \mathrm{A} \quad \mathrm{Eq}: \mathrm{2}
$$


em que,

$\mathrm{Q}=$ Vazão de escoamento $\left(\mathrm{m}^{3} \mathrm{~s}^{-1}\right)$

$\mathrm{V}=$ Velocidade do fluxo de água $\left(\mathrm{m} \mathrm{s}^{-1}\right)$

$\mathrm{A}=$ Área da seção molhada $\left(\mathrm{m}^{2}\right)$

No ponto 2, foi considerado a vazão conforme disposto pela INSTRUÇÃO NORMATIVA 04-2015, disponibilizado pela Secretaria de Meio Ambiente, Recursos Hídricos, Infraestrutura, Cidades e Assuntos Metropolitanos (SECIMA), que por meio da vazão específica fornecida $\left(\mathrm{L} \mathrm{s}^{-1} \mathrm{~km}^{-2}\right)$ e a área de contribuição $\left(\mathrm{km}^{2}\right)$, obtém-se uma vazão de referência ( $\left.\mathrm{Q}_{95 \%}\right)$. As medições de vazão nos demais pontos foram realizadas em todos os meses de coletas de água.

\section{Aporte de sedimentos}

O volume da represa foi determinado por meio da área molhada, obtida pelo Google Earth. Todas se assemelhavam a área de um triângulo. A profundidade foi obtida por meio de uma média de todas as represas, a qual foi de 2 metros (Equação 3).

$$
V=\frac{\mathrm{a} \cdot \mathrm{h}}{2} \cdot 2
$$

Eq.: 3

em que,

$\mathrm{V}=$ Volume da represa $\left(\mathrm{m}^{3}\right)$

$\mathrm{a}=$ área da represa $(\mathrm{m})$

$\mathrm{h}=$ profundidade de represa $(\mathrm{m})$

A densidade média do solo para o município de Rio Verde foi determinada por meio de estudos realizado por Ralisch et al. (2008), sendo o valor médio de $1,09 \mathrm{~g} \mathrm{~cm}^{-3}$.

\section{RESULTADOS E DISCUSSÃO}

\section{Uso e ocupação do solo}

As bacias 1 e 2 classificaram-se com uso do solo agrícola $66 \%$ e $22 \%$, e pastagem $12 \%$ e $23 \%$, respectivamente, sendo que $48 \%$ do uso do solo na bacia 2 é referente a matas (Tabela 3; Figura 3 e 4).

Tabela 3 - Classificação do uso do solo nas áreas da bacia de estudo.

\begin{tabular}{lcccc}
\hline & Uso do solo & \multicolumn{3}{c}{ Área da bacia (ha) } \\
\cline { 2 - 5 } & 1 & 2 & 3 & 4 \\
\hline Agricultura & 46,4 & 14,9 & 266,9 & 101,9 \\
Matas & 12,7 & 32,1 & 0,1 & 263,0 \\
Pastagem & 8,9 & 15,7 & 15,3 & 74,3 \\
Urbanização ou solo exposto & 2,0 & 3,2 & 538,6 & 549,3 \\
\hline Total & 70,0 & 65,9 & 820,9 & 988,5 \\
\hline
\end{tabular}

As bacias hidrográficas 3 e 4 caracterizaram-se com mais de $55 \%$ da área ocupada por urbanização ou solo exposto (Tabela 3; Figura 5 e 6), seguido de agricultura na bacia 3 com $32 \%$, e matas $10 \%$ na bacia 4 , respectivamente. 


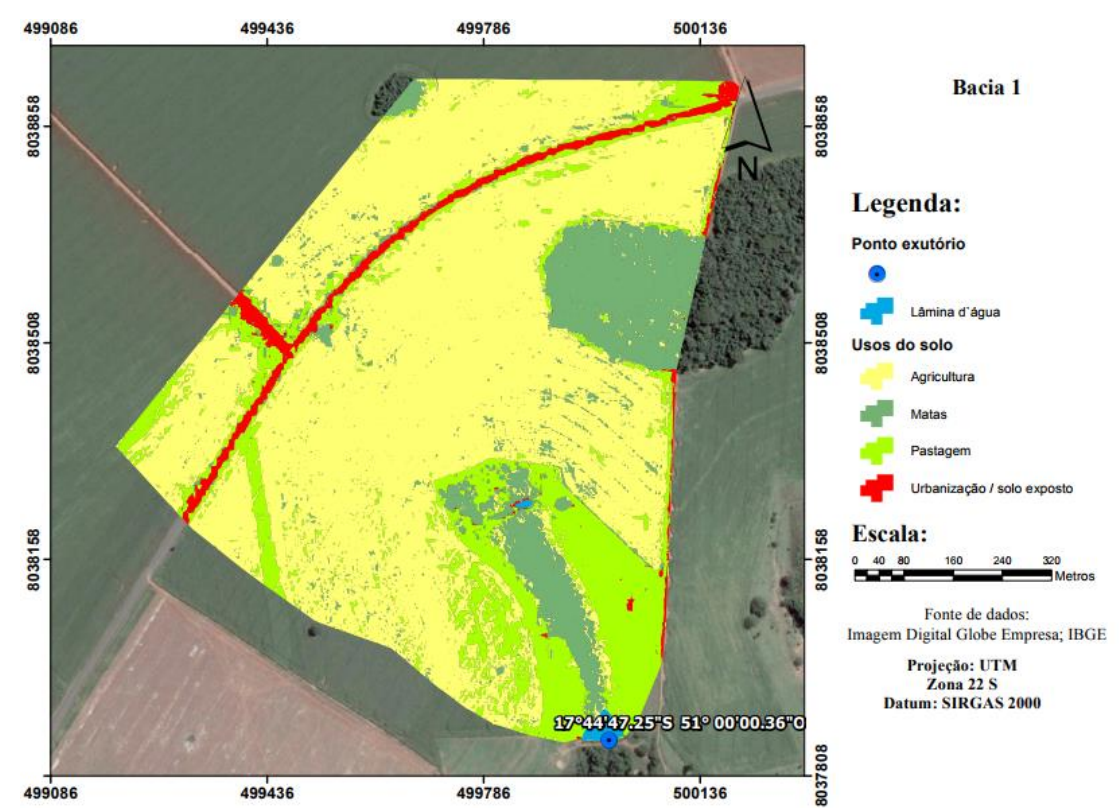

Figura 3 - Uso e ocupação do solo na bacia 1 do município de Rio Verde, Goiás.

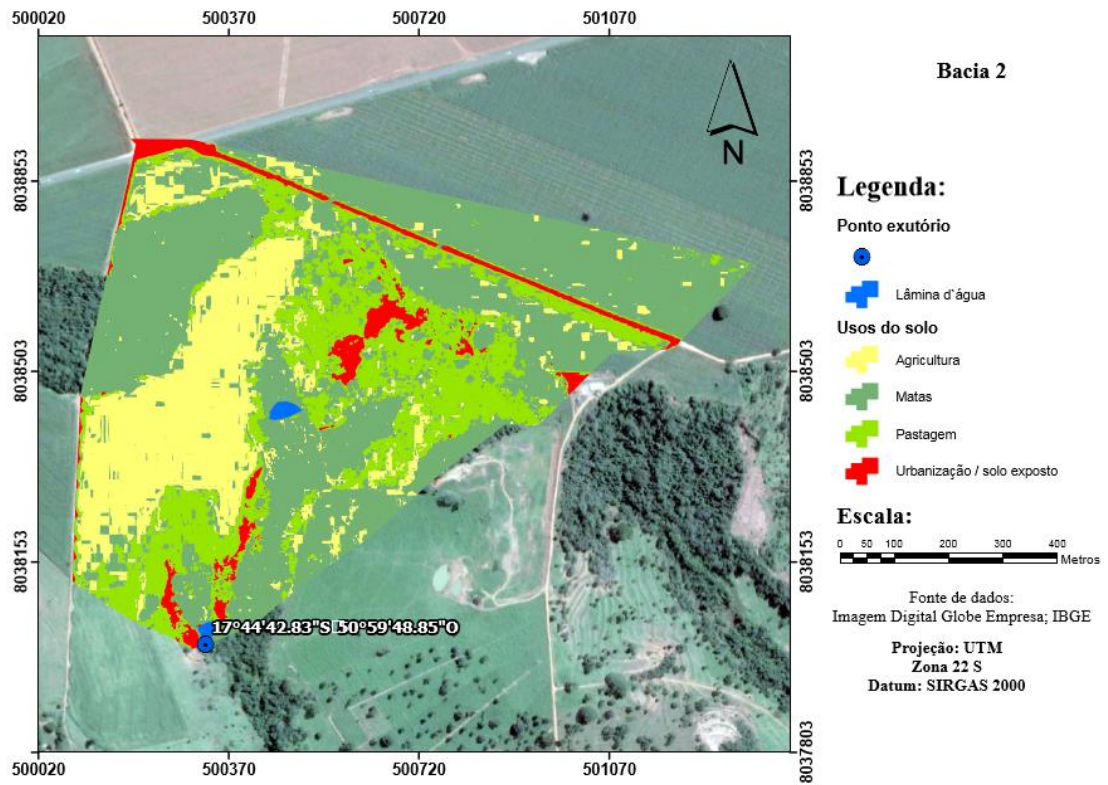

Figura 4 - Uso e ocupação do solo na bacia 2 do município de Rio Verde, Goiás. 


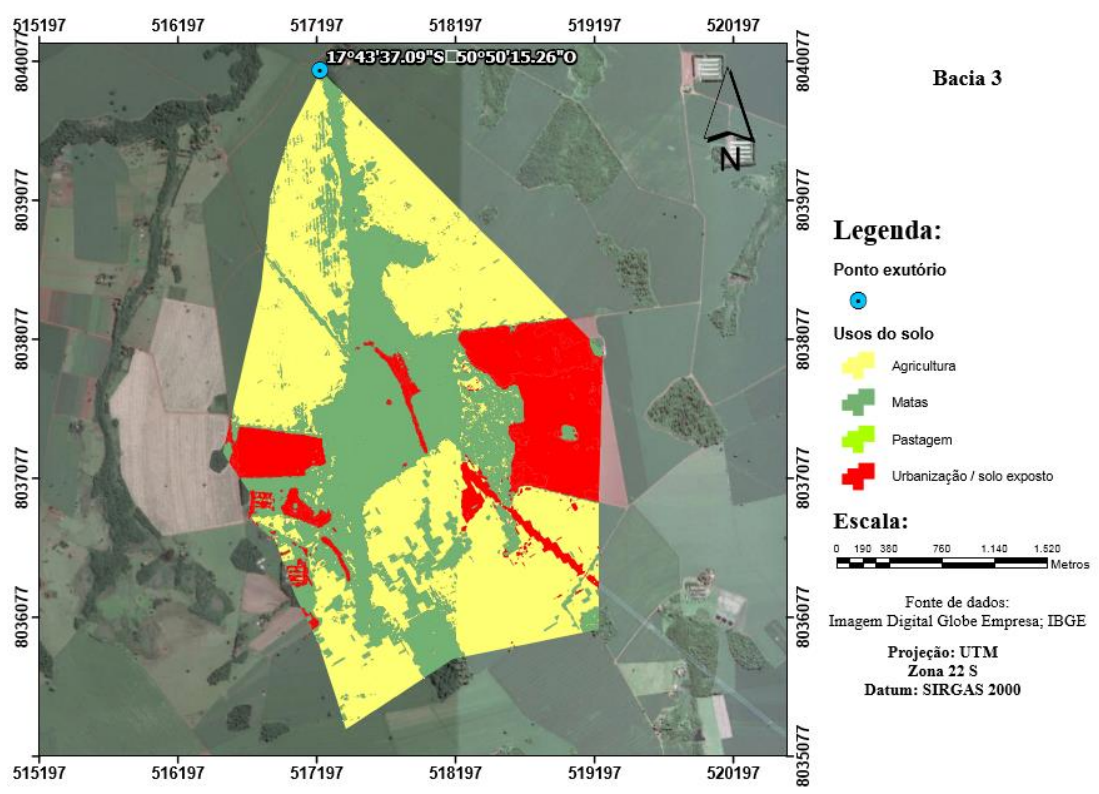

Figura 5 - Uso e ocupação do solo na bacia 3 do município de Rio Verde, Goiás.

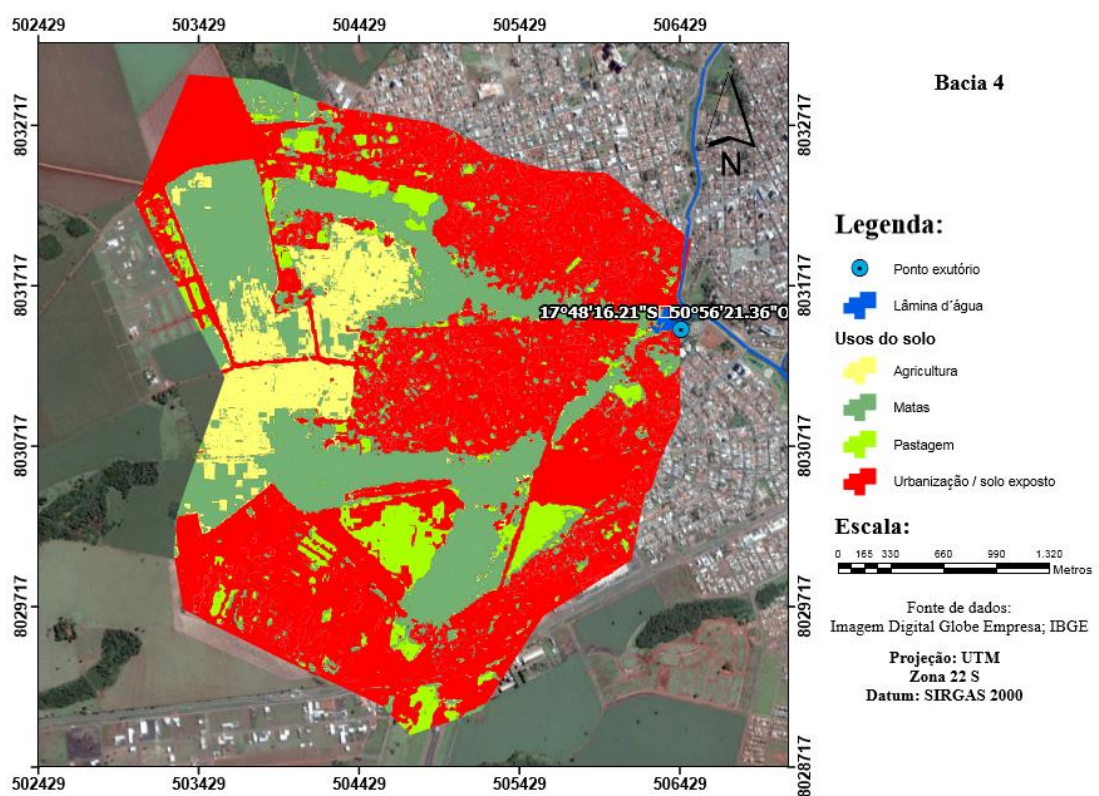

Figura 6 - Uso e ocupação do solo na bacia 4 do município de Rio Verde, Goiás.

\section{Turbidez}

Nos dois períodos avaliados e em todas as bacias hidrográficas, os valores de turbidez estavam dentro dos padrões estabelecidos pela resolução CONAMA 357 que é de até 100 UNT. O menor valor registrado foi de 1,52 UNT na bacia 1 e o máximo de
63,6 UNT na bacia 4. De maneira geral, a entrada de sedimentos na bacia 3 apresentou valores maiores, pois possui uma extensa área de solo exposto (538,6 ha), ocasionando processos erosivos que contribuem para o aumento da turbidez (Figura 7). 


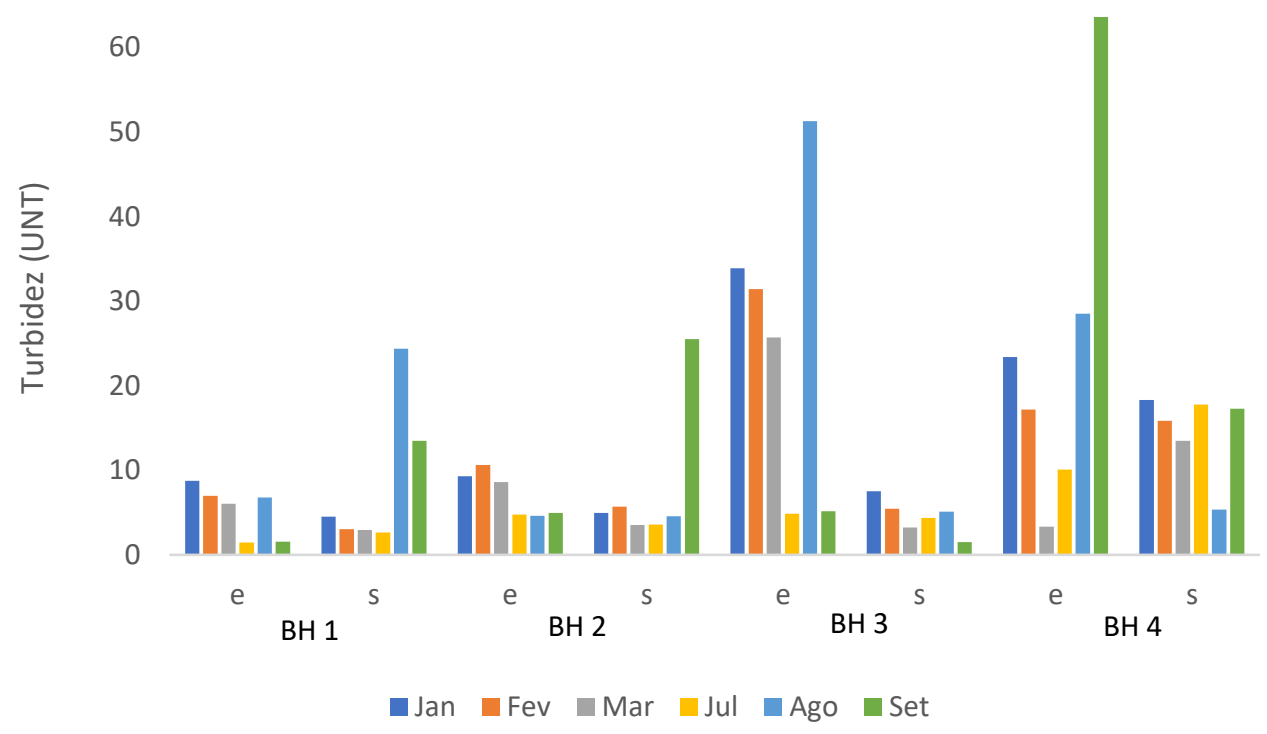

Figura 7 - Valores de turbidez nas bacias hidrográficas 1 a 4 na entrada e saída nos respectivos meses de coleta.

Em todos os pontos de monitoramento houve redução da concentração da turbidez na saída em relação a entrada, exceto nas bacias 1 e 2 , nas quais, no período estiagem, o gado faz uso do curso d'água para dessedentação, ocorrendo o pisoteamento da área revolvendo os sólidos e assim aumentando a turbidez.

No período chuvoso, a turbidez foi mais elevada devido ao processo de erodibilidade da bacia. Houve alguns pontos isolados, que no período de estiagem obteve concentrações maiores de turbidez, isso ocorre pela presença de bovinos na área e devido ao solo exposto e urbanização.

Segundo Rocha et al. (2016), os níveis de turbidez dificultam a passagem de raios solares, reduzindo o oxigênio dissolvido na água.

As bacias 3 e 4 , obtiveram as maiores concentrações de turbidez, ambas possuem área de urbanização/solo exposto com mais de 55\% da área total da bacia hidrográfica. A ausência de cobertura vegetal, contribui para o aumento da turbidez, pois a vegetação retém as partículas sólidas, para que não cheguem ao corpo hídrico.

\section{Alcalinidade}

Os maiores níveis de alcalinidade foram na bacia 4, devido a interferência urbana, na qual ocorre lançamento clandestino de esgoto (Figura 8).

$\mathrm{O}$ aumento da alcalinidade está relacionado ao aumento de sólidos dissolvidos, tendo como origem a decomposição da matéria orgânica e também o lançamento de dejetos industriais (Von Sperling, 2005).

As bacias 1, 2 e 3, tiveram níveis semelhantes, tanto na entrada como na saída da bacia, porém, no período de estiagem os índices de alcalinidade foram menores.

\section{Dureza}

As maiores concentrações de dureza foram no mês de julho e março, tanto no período seco quanto no período chuvoso (Figura 9). 


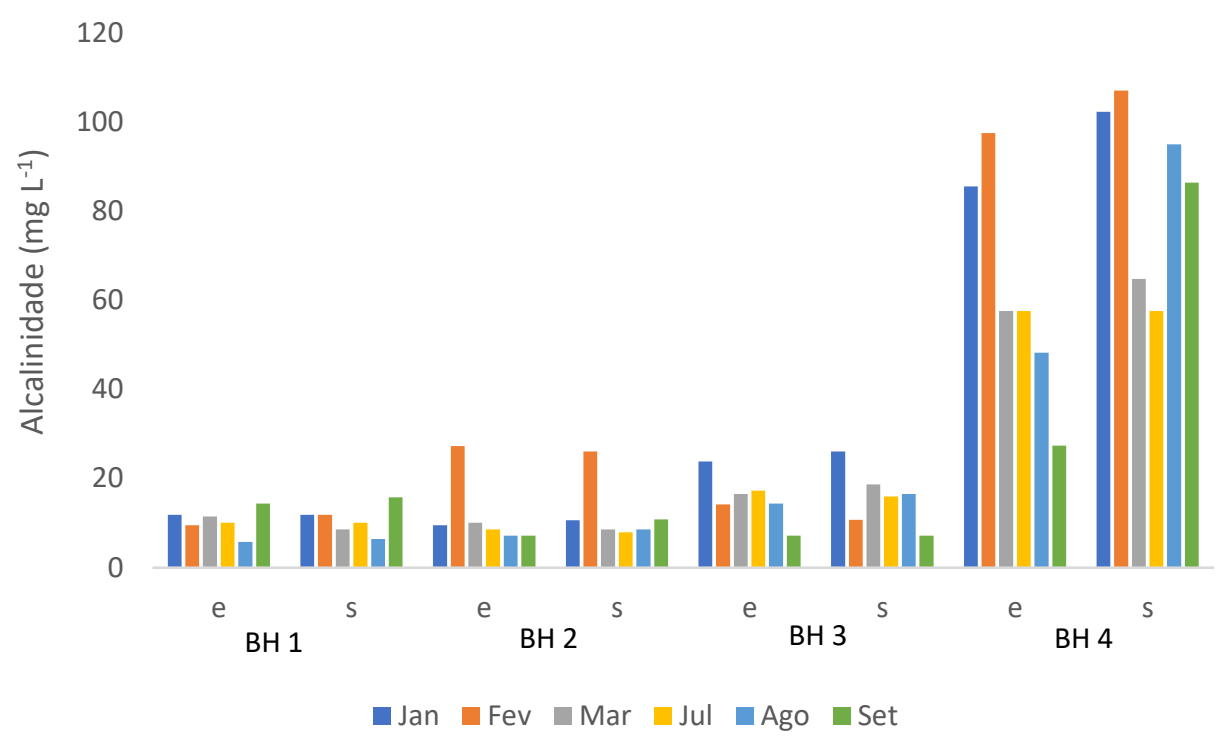

Figura 8 - Valores de alcalinidade nas bacias hidrográficas 1 a 4 na entrada e saída nos respectivos meses de coleta.

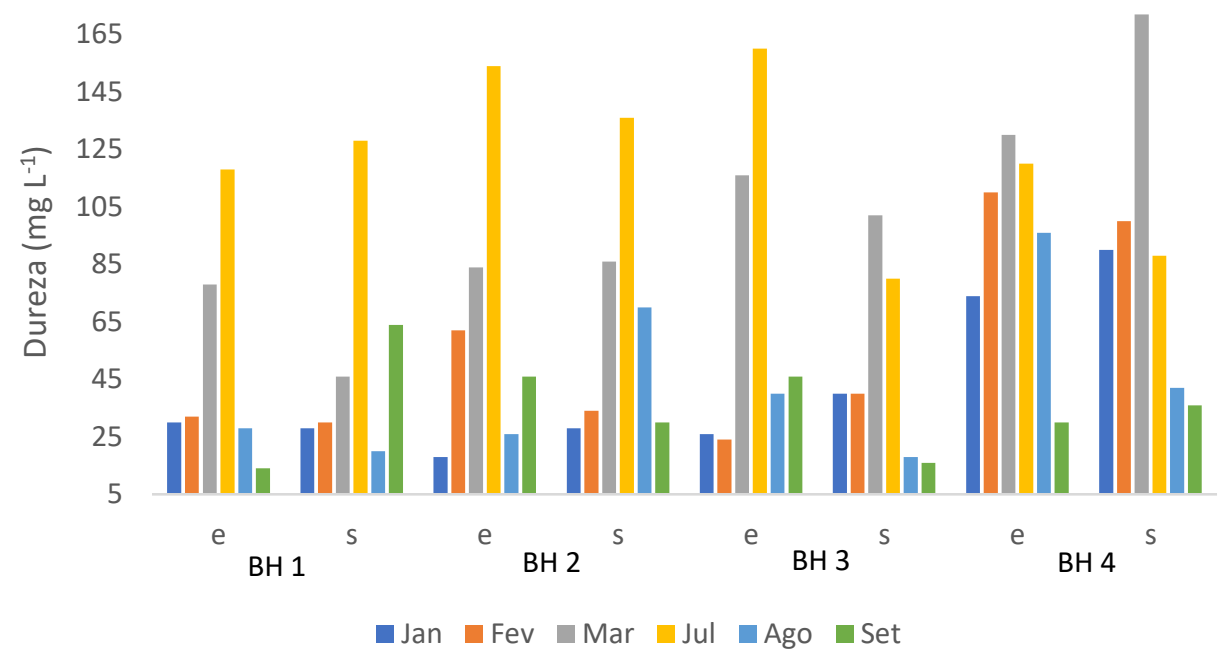

Figura 9 - Valores de dureza nas bacias hidrográficas 1 a 4 na entrada e saída nos respectivos meses de coleta.

Segundo Rocha e Pereira (2016) a dureza está relacionada a alcalinidade, por estar associada a carbonatos. A degradação das áreas de preservação permanente e a ausência de manejo do solo influenciam na degradação, principalmente no período de estiagem.

De acordo com Santos e Hernandez (2013), no período de estiagem, o intemperismo das rochas, a erosão e a ação antrópica do uso e ocupação do solo influenciam negativamente na qualidade da água, elevando os valores de cálcio e magnésio e na redução da vazão.

\section{Condutividade elétrica}

Obteve-se maior valor de condutividade elétrica na bacia 4, pois, esta possui uma extensa área de urbanização/solo exposto, na qual o lançamento clandestino de esgoto ocorre frequentemente, o solo exposto auxilia no carreamento de partículas sólidas 
para o corpo hídrico. Nas demais bacias, as

concentrações foram inferiores (Figura 10).

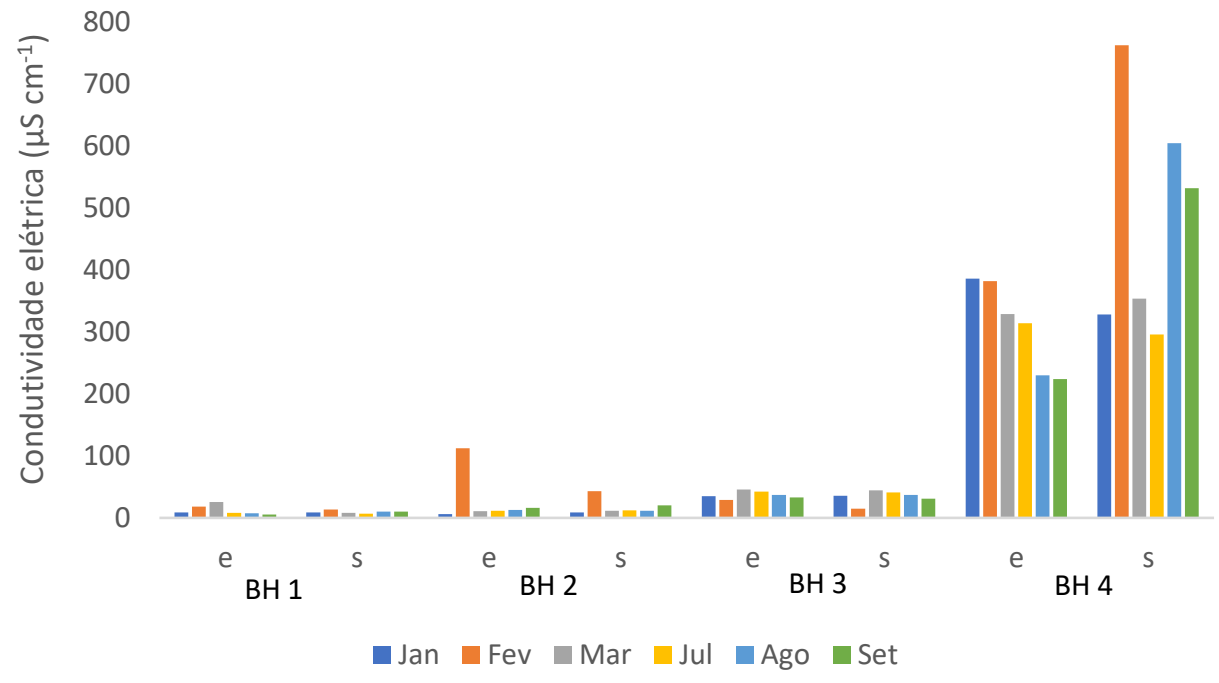

Figura 10 - Valores de condutividade nas bacias hidrográficas 1 a 4 na entrada e saída nos respectivos meses de coleta.

No período chuvoso os níveis de (Figura 11). Nota-se também que o pH na entrada foi condutividade foram maiores, nesse período ocorre carreamento de sólidos o que contribui para elevação do índice. $\mathrm{Na}$ bacia 4, somente na saída, ocorreu variação durante os períodos avaliados, por ser uma área de lançamento clandestino de esgoto.

Resultados semelhantes foram encontrados por Santos e Hernandez (2013), pois as concentrações de condutividade estão relacionadas com áreas onde ocorrem influência de concentrações elevadas de matéria orgânica por conta da adubação e das áreas degradadas, cujos sólidos são dissolvidos no corpo hídrico.

\section{Potencial Hidrogeniônico $(\mathrm{pH})$}

Os maiores níveis de $\mathrm{pH}$ foram na bacia 4 , pois o corpo hídrico possui uma grande quantidade de algas, maior que na saída em praticamente todos os períodos, pois a entrada possui um aporte de matéria orgânica maior que a saída. A represa, por ser um meio lêntico, ocorre a deposição da matéria orgânica ao longo do curso d'água.

De acordo com a Resolução CONAMA 357/2005, para corpos hídricos classe II, os níveis de pH são aceitáveis entre 6,0 e 9,0. No período de estiagem, praticamente em todas as bacias obteve-se parâmetros dentro do estabelecido pelo CONAMA, já no período chuvoso, o $\mathrm{pH}$ obteve valores predominantemente mais ácido. No período de estiagem, somente na bacia 1 e 2 obteve-se valores inferiores a 6,0 sendo o menor valor 4,67 e o maior de 7,24 para o mesmo período. No período chuvoso, o índice mínimo foi 5,5 e máximo 7,53, obtendo média 6 . o que contribui para que o meio se torne alcalino 


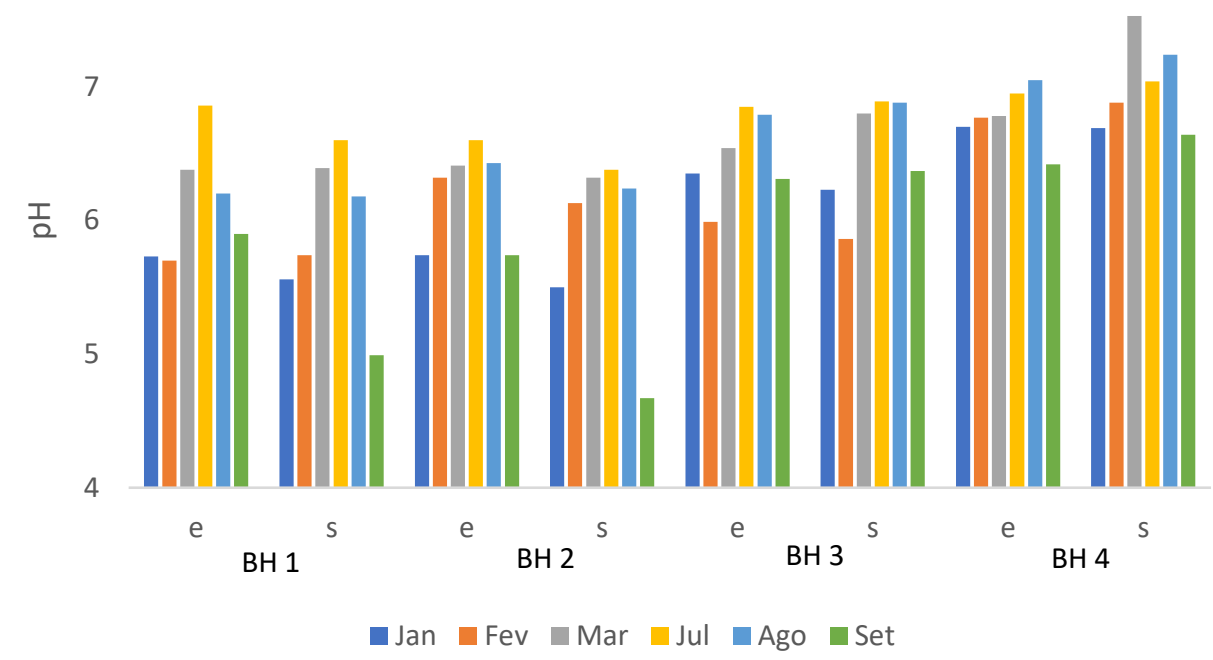

Figura 11 - Valores de dureza nas bacias hidrográficas 1 a 4 na entrada e saída nos respectivos meses de coleta.

\section{Potencial de assoreamento - Sólidos totais}

O uso e ocupação do solo influencia no processo de carreamento de sedimentos para as represas, diminuindo a qualidade e a quantidade de água no corpo hídrico, logo é necessário conhecimento de toda a bacia hidrográfica para que ocorra um planejamento e gestão da mesma. No período chuvoso houve maior concentração de sólidos totais decantados nos pontos respectivos 4, 1, 3 e 2 (Tabela 4).

Tabela 4 - Decantação de sólidos totais no período chuvoso em represas do município de Rio Verde, Goiás.

\begin{tabular}{cccc} 
Bacia & Entrada $\left(\mathrm{kg} \mathrm{L}^{-1}\right)$ & Saída $\left(\mathrm{kg} \mathrm{L}^{-1}\right)$ & Decantação $\left(\mathrm{kg} \mathrm{L}^{-1}\right)$ \\
\hline 1 & $141,6 \cdot 10^{-6}$ & $53,3 \cdot 10^{-6}$ & $88,3 \cdot 10^{-6}$ \\
2 & $65,0 \cdot 10^{-6}$ & $46,6 \cdot 10^{-6}$ & $18,4 \cdot 10^{-6}$ \\
3 & $85,0 \cdot 10^{-6}$ & $26,6 \cdot 10^{-6}$ & $58,4 \cdot 10^{-6}$ \\
4 & $646,6 \cdot 10^{-6}$ & $361,6 \cdot 10^{-6}$ & $285 \cdot 10^{-6}$ \\
\hline
\end{tabular}

No período de estiagem houve maior (urbanização/solo exposto), 2 (agrícola/pastagem) e 3 concentração de sólidos totais decantados no ponto 4 (área agrícola) (Tabela 5).

Tabela 5 - Decantação de sólidos totais no período de estiagem em represas do município de Rio Verde, Goiás.

\begin{tabular}{cccc}
\hline Bacia & Entrada $\left(\mathrm{kg} \mathrm{L}^{-1}\right)$ & Saída $\left(\mathrm{kg} \mathrm{L}^{-1}\right)$ & Decantação $\left(\mathrm{kg} \mathrm{L}^{-1}\right)$ \\
\hline 1 & $150 \cdot 10^{-6}$ & $200 \cdot 10^{-6}$ & $-50,0 \cdot 10^{-6^{*}}$ \\
2 & $183,3 \cdot 10^{-6}$ & $66,6 \cdot 10^{-6}$ & $116,7 \cdot 10^{-6}$ \\
3 & $100,0 \cdot 10^{-6}$ & $65,0 \cdot 10^{-6}$ & $35,0 \cdot 10^{-6}$ \\
4 & $416,6 \cdot 10^{-6}$ & $250,0 \cdot 10^{-6}$ & $166,6 \cdot 10^{-6}$ \\
\hline
\end{tabular}

* 0 valor de entrada de saída de sólidos totais da represa foi inferior a entrada devido a presença de animais na área (jusante da represa) que provocava a movimentação de sedimentos na água, elevando assim a quantidade de sólidos totais. Porém, este resultado não representa que a represa não corra riscos de assoreamento, pois há uma contribuição constante de sedimentos na mesma (entrada) e a saída só ocorre na presença de animais na área para sedentação.

Na bacia 1, no período chuvoso, o índice de decantação foi de $88,3 \cdot 10^{-6} \mathrm{~kg} \mathrm{~L}{ }^{-1}$, segunda maior concentração, pois o processo de precipitação propicia o aumento do escoamento de sólidos. No período de 
estiagem, os sólidos totais na saída foram maiores que no valor da entrada, este fator ocorreu porque neste período o gado fica alojado mais próximo do curso d'água, utilizando-o de maneira frequente para dessedentação.

A represa ainda tem influência de área agrícola (66,3\%), na qual não possui o manejo adequado do solo, com uma declividade elevada de 4,2\%, favorecendo o despejo de partículas sólidas para o curso d'água.

Na bacia 2, os níveis de sólidos no período de estiagem foram maiores comparados ao período chuvoso, pelo mesmo fator da bacia 1. O curso d'água não é cercado devidamente, o gado o utiliza para dessedentação, o que contribui para o aumento de sólidos no curso. Esta bacia possui área com mata de 48,7\%, que forma uma barreira de contenção, para que, no período chuvoso, as partículas sólidas não cheguem ao curso d'água.

Na bacia 3, a decantação de sólidos no corpo hídrico, foi maior no período chuvoso, pois esta bacia possui uma grande área de solo exposto, sendo de 65,6\%, que é um fator fundamental para o carreamento de sedimentos para curso d'água. $O$ cultivo sem o manejo adequado é outro fator que explica os dados obtidos, a área cultivada é de 32,5\%, e não possui manejo adequado do solo, como curvas de nível e bacias de retenção.

A bacia 4 obteve o maior índice de decantação de sólidos nos dois períodos avaliados. A interferência urbana é o principal fator para a taxa de sedimentos no corpo hídrico, causados por lançamentos clandestinos e poluição difusa advindos das áreas urbanas.

A quantificação de sedimentos decantados nas represas monitoradas está descrito nas Tabela 6 e 7 .

Tabela 6 - Caracterização das médias de sedimentos decantados no período chuvoso dos pontos de análise das represas do município de Rio Verde, Goiás.

\begin{tabular}{cccc}
\hline Ponto & Decantação $\left(\mathrm{kg} \mathrm{L}^{-1}\right)$ & Vazão $\left(\mathrm{L} \mathrm{s}^{-1}\right)$ & Sedimentos decantados $\left(\mathrm{t} \mathrm{dia}{ }^{-1}\right)$ \\
\hline 1 & $88,3 \cdot 10^{-6}$ & 7,2 & 0,055 \\
2 & $18,4 \cdot 10^{-6}$ & 1,1 & 0,002 \\
3 & $58,4 \cdot 10^{-6}$ & 89,7 & 0,453 \\
4 & $285 \cdot 10^{-6}$ & 216,8 & 5,338 \\
\hline
\end{tabular}

Tabela 7 - Caracterização das médias de sedimentos decantados no período de estiagem dos pontos de análise das represas do município de Rio Verde, Goiás.

\begin{tabular}{cccc}
\hline Ponto & Decantação $\left(\mathrm{kg} \mathrm{L}^{-1}\right)$ & Vazão $\left(\mathrm{L} \mathrm{s}^{-1}\right)$ & Sedimentos decantados $\left(\mathrm{t} \mathrm{dia}{ }^{-1}\right)$ \\
\hline $1^{*}$ & - & - & - \\
2 & $116,7 \cdot 10^{-6}$ & 1,1 & 0,011 \\
3 & $50,0 \cdot 10^{-6}$ & 37,4 & 0,162 \\
4 & $166,6 \cdot 10^{-6}$ & 191,0 & 2,749 \\
\hline
\end{tabular}

*Ver Tabela 5.

No período chuvoso, a taxa de carreamento de sedimentos em corpos hídricos eleva-se, devido às más condições de manejo, é fundamental o planejamento das propriedades para manter a quantidade e a qualidade do curso d'água. No período de estiagem há uma alta taxa de carreamento de sedimentos em bacias que possuem pastagem, logo, faz-se necessário o cercamento das áreas, para evitar que animais possam chegar ao corpo hídrico, aumentando a quantidade de partículas sólidas e o assoreamento da represa.

A principal forma de gestão da bacia hidrográfica é o manejo adequado da área, é indispensável a implantação de manejo do solo para diminuir as taxas de carreamento de sedimentos. É necessário o conhecimento da bacia como um todo, 
para que não ocorra influência e contribuição de outros poluentes.

A elevada quantidade de sedimentos das represas podem acarretar diversos impactos negativos, à fauna, à flora, ao ecossistema e à saúde humana, ocasionando a mortalidade de peixes e espécies aquáticas da região, entupimento de tubulações, redução da vazão e do volume útil de represas, diminuição do oxigênio, além de inundações que podem prejudicar as culturas e animais presentes no meio.

A quantidade de sedimentos decantados em uma represa, causa assoreamento, comprometendo sua vida útil, não sendo mais possível o armazenamento de água nas bacias 1, 2, 3 e 4, em aproximadamente, 456, 536, 85 e 22 anos, respectivamente.

A bacia 4 de influência de urbanização/solo exposto é a que mais possui sedimentos, consequentemente, maior potencial de assoreamento. Assim, em aproximadamente 22 anos, esta estará totalmente assoreada, comprometendo as atividades desenvolvidas no local.

$\mathrm{Na}$ quantificação dos sedimentos totais decantados em represas, nota-se um valor baixo de concentração de poluentes, mas, deve ser analisado e acompanhado, realizando o manejo adequado da área, pois os sedimentos são acumulativos e este teor, em determinado tempo, pode assorear os cursos d'água, perdendo toda a vazão do corpo hídrico, tornando o processo dificilmente reversível.

\section{CONCLUSÕES}

A qualidade da água e o potencial de assoreamento nas represas analisadas, foram mais significativos na bacia 4 que possui uma área com mais de $55 \%$ da área total ocupada por urbanização/solo exposto. Este fator contribuiu para aumento de carreamento de sedimentos no corpo hídrico, além da alta taxa de carga orgânica lançada clandestinamente que irá alterar a qualidade no curso pelos parâmetros monitorados, no período chuvoso tende a aumentar os sedimentos decantados, causando assoreamento e diminuição da qualidade.

As bacias que possuem área com matas contribuiu para a retenção de partículas sólidas nas represas e com isto evitou que outros parâmetros físicoquímico apresentassem alterações elevadas de sua qualidade.

Nas bacias que possuem influência de uso e ocupação do solo de pastagem é necessário um planejamento para que o gado e outros animais não possam chegar próximo ao corpo hídrico, pois o mesmo causa o revolvimento dos sólidos e aumento da turbidez, que diminui a penetração de luz no curso d'água.

\section{REFERÊNCIAS}

ACQUA NHD, SILVA GP, BENITES VM, ASSIS

RL, SIMON GA. Métodos de amostragem de solos em áreas sob plantio direto no sudoeste goiano. Rev Bras de Eng Agr e Amb. 2013; 17:117-122.

\section{AMERICAN PUBLIC HEALTH ASSOCIATION.}

Standard methods for the examination of water and wastewater. 20 ed. New York: United Book, 2005.

APARECIDO CFF, VANZELA LS, VAZQUEZ GH,

LIMA RC. Manejo de bacias hidrográficas e sua influência sobre os recursos hídricos. Irriga. 2016; 21:239-256. doi: 10.15809/irriga.2016v21n2p239-256.

Ministério do Meio Ambiente. Resolução n.357, de 17 de março de 2005. Conselho Nacional do Meio Ambiente. 
BUCCI, MMHS. Análise de metais, agrotóxicos, parâmetros físico-químicos e microbiológicos nas águas da Represa Dr. João Penido, Juiz de Fora, MG. Rev Amb e Água. 2015; 10:804-824. doi: 10.4136/ambi-agua.1534.

CASTRO PAL, SANTOS GO. Caracterização climática do município de Rio Verde, Goiás, como ferramenta de gestão, planejamento e tomada de decisão na área urbana e rural. In: Anais do $12^{\circ}$ Circuito de Iniciação Científica da Universidade de Rio Verde; junho 2018; Rio Verde. Rio Verde: Universidade de Rio Verde; 2018. p. 67-71.

COMITÊ DE BACIAS HIDROGRÁFICAS DO RIO PARANAÍBA (CBH PARANAÍBA). Municípios da Bacia. 2015 [acesso em 24 ago 2015]. Disponível em: $\leq$ http://www.cbhparanaiba.org.br/>.

FREIRE, FGC, BATISTA, RO, SILVA, PCM, COSTA, SC, OLIVEIRA, AFM. Indicadores de qualidade da água no rio Jaguaribe em São João do Jaguaribe-CE, Brasil. Irriga. 2013; 18:700-707. doi: 10.15909/irriga.2013v18n4p700.

\section{INSTITUTO NACIONAL DE METEOROLOGIA} (INMET). 2017. Dados climáticos da Estação de Rio Verde: série histórica de 1961 a 2017. Banco de dados do Instituto Nacional de Meteorologia.

\section{INSTITUTO BRASILEIRO DE GEOGRAFIA E} ESTATÍSTICA (IBGE). Censo demográfico. 2010. 2017 [acesso em 24 ago 2017]. Disponível em:

$\leq$ http://www.ibge.gov.br/home/estatistica/p opulacao/censo2010/tabelas pdf/total popul acao goias.pdf. $>$.
LIMA EACF, SILVA HR, ALTIMARE AL. Uso atual da terra no município de Ilha Solteira, SP, Brasil: riscos ambientais associados. Hol Env. 2004;4:81-96. doi: 10.14295/holos.v4i2.353.

NBR 9.898. Preservação e técnicas de amostragem de efluentes líquidos e corpos receptores, 1987.

\section{PAULA MR, BENEDETTII ACP, PEREIRA FILHO} W. Influência do uso e cobertura da terra aliado à precipitação pluviométrica na qualidade da água da Bacia Hidrográfica do Rio Ingaí-RS/ Brasil. Rev do Dep de Geo. 2016; 32:143-152. doi: 1011606/rdg.v32i0.119330.

RALISCH R, MIRANDA TM, OKUMURA RS, BARBOSA GMC, GUIMARÃES MF, SCOPEL E, BALBINO LC. Resistência à penetração de um Latossolo Vermelho Amarelo do Cerrado sob diferentes sistemas de manejo. Rev Bras de Eng Agr e Amb. 2008;12:381-384.

ROCHA E, REYS P, SILVA PO, SOARES MP. Florística e Fitossociologia em um fragmento de cerrado no sudoeste de Goiás. Rev Glo Sci and Tec. 2014; 7:110-118. doi: 10.14688/19843801/gst.v7n3p110-118.

ROCHA CHB, PEREIRA AM. Análise multivariada para seleção de parâmetros de monitoramento em manancial de Juiz de Fora, Minas Gerais. Rev Amb Água. 2016;11: 176-187. doi: 10.4136/1980-993X.

ROCHA CHB, SILVA TM, FREITAS FA. Processos condicionantes de alterações em variáveis limnológicas: uma abordagem estatística na Represa de São Pedro, Juiz de Fora (MG). 
Engenharia Sanitária Ambiental. 2016; 21:131-

138. doi: 10.1590/S141341520201600100113419.

SANTOS GO, HERNANDEZ FBT. Uso do solo e monitoramento dos recursos hídricos no Córrego do Ipê, Ilha Solteira, SP. Rev Bras de Eng Agrí e Amb. 2013;17:60-68. doi: 10.1590/S1415-43662013000100009.

SECIMA, Secretaria de Meio Ambiente, Recursos Hídricos, Infraestrutura, Cidades e Assuntos Metropolitanos. INSTRUÇÃO NORMATIVA 04-2015. 2015 [acesso em 24 ago 2017].
Disponível em: <http://www.sgc.goias.gov.br/upload/arquivo s/2016-06/instrucao-normativa-04-2015.pdf $>$.

VANZELA LS, SOUZA RA, PITARO FAM, SILVA PAF, SANCHES AC. Influência da ocupação do solo e do excedente hídrico sobre a vazão e transporte de sedimentos. Irriga. 2012;181-191. doi: 10.15809/irriga.2012v1n01p181.

VON SPERLING M. Introdução à qualidade das águas e ao tratamento de esgotos. 3ed. Belo Horizonte: Imprensa Universitária da UFMG; 2005. 